\title{
Meta-Analysis in Young Children's Robotics Learning to Categorize Meaningful Keywords
}

\author{
Sung-eun Jung ${ }^{1}$ and Eun-sok Won ${ }^{2}$ \\ ${ }^{1}$ The University of Georgia \\ ${ }^{2}$ Mokwon University \\ ${ }^{1}$ sungeun@uga.edu, ${ }^{2}$ lastgoodman@hanmail.net
}

\begin{abstract}
This study is intended to serve as a meta-analysis of the existing literature on robotics education for young children (pre-K and kindergarten through $5^{\text {th }}$ grade). Through a systematic review, this study categorized the key themes of the existing studies, concluding that the current research trend in young children's robotics learning is weighted toward the outcomefocused research. This study's results suggest that this research trend will establish the impact of robotics education through strong evidence, thus advocating for an instrumental view of robotics education as a means of not only advancing young children's skills in other subject areas but also aiding in their holistic development. This study thus implies a need for expanded research on young children's needs and challenges when learning robotics and on their access to STEM areas.
\end{abstract}

Keywords: Robotics, Early Childhood Education, STEM

\section{Introduction}

The rapidly changing technological environment and the complexity of contemporary society require innovative and knowledgeable citizens. The growing attention given to science, technology, engineering, and mathematics (STEM) has created societal expectations that education should cultivate competent future workers who have the capability to adapt to technology-driven conditions [1].

Robotics education is one response to these needs, and the knowledge and skills that this form of education can provide help to meet those needs. Robotics education provides learners with practical experiences to help them understand technological language and systems, adapt to and accept the constant changes found in complex environments, and utilize their knowledge in real situations, regardless of time, space, and context [2]. In addition, robotics education has been suggested as a solution for the lack of student achievement in STEM subjects [3]. The use of physical and attractive robotics environments in education is expected to motivate students to achieve in STEM subjects and, ultimately, to seek careers in those areas.

Regardless of economic and societal needs, robotics education has scholars' attention because of the significance of empowering learners through authentic learning. By engaging in sensory-based, process-oriented experiences, young students can take on crucial roles as co-constructors of learning rather than as passive knowledge receivers [4, 5]. The problem-solving processes and the engineering design approach used in robotics activities can open a wider space in which students can connect their learning situations to issues from ordinary life.

In recent years, there has been renewed interest in the pedagogical concerns related to young students. Researchers have presented the potential of robotics education for young learners, moving beyond issues with their ages. In addition, by developing and

Received (November 26, 2017), Review Result (January 26, 2018), Accepted (February 1, 2018) 
implementing a robotics curriculum with tangible robots (involving topics such as introductory programming) for K-12 students, researchers have created a concrete picture of robotics education that practitioners can use.

However, the research on robotics education is still in its early stages. Thus, despite the recent attention, much uncharted terrain remains. In particular, given young children's tendencies toward sensory engagement and object-based exploration, robotics education can be used in parallel with these children's learning trajectories [6]. However, despite the rise in studies focusing on young children, few comprehensive investigations of young children's robotics learning have been conducted.

In this study, we aim to depict children's robotics learning by reviewing the existing literature on this topic, with an emphasis on young learners (pre-K and kindergarten through $5^{\text {th }}$ grade). To achieve this purpose, our review study is guided by the following question: "What key topics does the existing research present with regard to young children's robotics learning?" In answering this question, we attempt to categorize and thematize the key findings of the existing studies on young children's robotics learning.

Our study consists of three sections. First, we describe the procedure for this systematic review. Next, we present the synthesized and analyzed results of the relevant studies based on our research question. Then, we discuss future research directions in robotics education and address the strengths and limitations of the existing studies.

\section{Procedure}

To establish a reliable literature review, we used the systematic review process suggested by Davies and colleagues [7] and by Pettigrew and Roberts [8]. Through purposeful questions, a systematic review explicitly identifies, appraises, and synthesizes all the relevant studies to answer questions rather than to simply summarize particular issues. Therefore, this process supports our goals of both acquiring cumulative knowledge of robotics education for young children and conducting a rigorous, critical literature review.

The specific steps for this review process are as follows:

1) Deciding on the scope of the review and developing the criteria

2) Searching for the relevant studies (applying the criteria)

3) Screening the studies (applying the criteria)

4) Analyzing the selected studies in conjunction with the research question

5) Synthesizing the findings

6) Drawing conclusions

At the very first stage, we began to develop explicit criteria to search and select relevant literature. The following seven criteria were applied for this review study:

1) Ages of Targeted Children: Even though our study targets kindergartener-age groups, the number of international studies targeting kindergarteners and preschoolers was relatively very small. Thus, in order to conduct a more comprehensive review, we included international studies which focused on Pre-K through $5^{\text {th }}$ or $6^{\text {th }}$. In the case of Korean journal, we searched studies only targeting kindergarten children (age 3-5).

2) Contents of Research: We included journal articles that examined robotics education as learning objects and contents - a kind of disciplines. Also, we included studies that viewed robotics education as educational tools for teaching and learning in other discipline areas such as literacy, math, science, and arts. Selective empirical studies provided young learners with robotics programs and curriculums.

3) Types of Robotic Technologies: Included studies should have employed Educational Robotics (ER) with the exception of Socially Assistive Robots (SAR) and intelligent robots. ER typically consists of different construction parts of robots (e.g., sensors, 
controllers, actors) and graphic-based programming interfaces that allow children to construct, operate, or program robots [9] Because we paid attention to young children's robotics-specific learning and pedagogical application of robots, we excluded the studies used SAR in this study. If the research used only software programs, iPad, or computers without physical robotics kits, those studies were also excluded.

4) Types of Research: Both quantitative and qualitative studies were embraced in this review study. However, conceptual papers, review papers, and book chapters were excluded.

5) Research Settings: We included both informal and formal settings in which children experienced robotics education programs or robotics activities.

6) Years of Publications: We limited the years of publications of the academic journals to the last 10 years — between 2006 and 2017.

7) Types of Publication: Our search for this review work was limited to finding journal articles including conference papers. Articles written in English and Korean were considered.

Based on these criteria, articles were searched through five online databases: ERIC (Educational Resources Information Center), Science Direct, Springer Link, Google Scholar, and RISS. The following three key words were used together at the initial searching stage: "Robotics," "Children," and "Education." In the case of Google Scholar, because it had a vast body of search results (18,000 results), we replaced "Children" with "Kindergarten." A specific search protocol was used to set subdiscipline or limited topics as Table 1 shows below.

Based on these criteria, articles were searched through five online databases: ERIC (Educational Resources Information Center), Science Direct, Springer Link, Google Scholar, and RISS. The following three key words were used together at the initial searching stage: "Robotics," "Children," and "Education." In the case of Google Scholar, because it had a vast body of search results (18,000 results), we replaced "Children" with "Kindergarten." A specific search protocol was used to set subdiscipline or limited topics as Table 1 shows below.

Table 1. Search Protocols

\begin{tabular}{|c|c|c|}
\hline Database & Search Protocol & $\begin{array}{c}\text { Number of } \\
\text { Results }\end{array}$ \\
\hline ERIC & $\begin{array}{l}\text { Search Terms: 'Robotics' AND ‘Education' AND } \\
\text { 'Children' } \\
\quad \downarrow \\
\text { Search Under: 'Journals' }\end{array}$ & $\begin{array}{c}86 \text { results } \\
\downarrow \\
56 \text { results }\end{array}$ \\
\hline $\begin{array}{c}\text { Science } \\
\text { Direct }\end{array}$ & $\begin{array}{l}\text { Search Terms: ‘Robotics' AND 'Education' AND } \\
\text { 'Children' } \\
\quad \downarrow \\
\text { Limit-to topics: 'Child' / 'Students' }\end{array}$ & $\begin{array}{c}1,475 \text { results } \\
\downarrow \\
112 \text { results }\end{array}$ \\
\hline $\begin{array}{l}\text { Springer } \\
\text { Link }\end{array}$ & $\begin{array}{l}\text { Search Terms: 'Robotics' AND 'Education' AND } \\
\text { 'Children' } \\
\quad \downarrow \\
\text { Search Under: 'Education \&Language' } \\
\quad \downarrow \\
\text { Search Subdiscipline: 'Learning \&Instruction' }\end{array}$ & $\begin{array}{c}1,871 \text { results } \\
\downarrow \\
254 \text { results } \\
\downarrow \\
115 \text { results }\end{array}$ \\
\hline $\begin{array}{l}\text { Google } \\
\text { Scholar }\end{array}$ & $\begin{array}{l}\text { Search Terms: ‘Robotics' AND 'Education' AND } \\
\text { 'Kindergarten' } \\
\quad \downarrow \\
\text { Excluded words: 'Socially Assistive Robotics' }\end{array}$ & $\begin{array}{c}3,020 \text { results } \\
\downarrow \\
339 \text { results }\end{array}$ \\
\hline
\end{tabular}




\begin{tabular}{|c|c|c|}
\hline RISS & $\begin{array}{l}\text { Search Terms: ‘Robotics' AND 'Education' AND } \\
\text { 'Kindergarten' } \\
\downarrow \\
\downarrow\end{array}$ & $\begin{array}{c}309 \text { results } \\
\downarrow \\
189 \text { results }\end{array}$ \\
\hline
\end{tabular}

However, as Table 2 shows, although we searched for articles using specific criteria, we found many irrelevant or overlapping results. Through several screenings, we reviewed the abstracts of the articles and excluded the following types of articles (all based on articles found using ERIC): 1) duplicate studies with the same authors, 2) research aimed at investigating robotics in terms of rehabilitation or using a clinical approach, 3) articles in which teachers were the main participants, 5) studies that used software programs with only virtual (not physical) robots, and 6) research that included young children only as test users to develop robotic technology. In summary, as Table 2 shows, we selected 49 relevant articles for use in our analysis.

Table 2. The Process of Screening and Numbers of Results

\begin{tabular}{|c|r|r|r|c|}
\hline \hline Database & Initial Results & $1^{\text {st }}$ Screening & $2^{\text {nd }}$ Screening & Final Screening \\
\hline \hline ERIC & 56 results & 41 results & 27 results & 23 results \\
\hline Science Direct & 112 results & 56 results & 19 results & 6 results \\
\hline Springer Link & 115 results & 47 results & 15 results & 6 results \\
\hline Google Scholar & 339 results & 98 results & 36 results & 11 results \\
\hline RISS & 189 results & 52 results & 12 results & 3 results \\
\hline $\begin{array}{c}\text { The Total } \\
\text { Number }\end{array}$ & & & & 49 results \\
\hline
\end{tabular}

In the analysis process, we read the entirety of each article and outlined the basic information presented therein (e.g., the ages of the participant children, the settings, the educational robots used, the research methods, the robotics education curricula, and the major findings). We then comprehensively reviewed the key characteristics of each research study and, relying on this review study's research question, analyzed and systematically categorized the patterns of our analysis results.

\section{Findings}

We identified the key topics in the existing research with regard to young children's robotics learning and determined which aspects of this type of learning that the existing studies investigated. Table 3 shows a thematically categorized breakdown of the studies' key topics, listing the six themes and the studies relevant to those themes. 
Table 3. Key Themes of Research Topics

\begin{tabular}{|c|c|}
\hline Themes of Research Topics & Number \\
\hline Outcomes of Robotics Learning & 30 \\
\hline $\begin{array}{l}\text { - Di Leito, Inguaggiato, Castro, Cecchim Ciono, Dell'Omo, \& Dario [10] } \\
\text { - Kopcha, McGregor, Shin, Qian, Choi, Hill, \& Choi [11] } \\
\text { - Sullivan \& Bers [12] } \\
\text { - Sullivan, Bers, \& Mihm [13] } \\
\text { - Bennie, Corbett, \&Palo [14] } \\
\text { - Gordon, Rivera, Ackermann, \& Breazeal [15] } \\
\text { - Julià \& Antolí [16] } \\
\text { - Sullivan \& Bers [17] } \\
\text { - Zaharija, Mladenović, \& Boljat [18] } \\
\text { - Bers, Flannery, Kazakoff, \&Sullivan [19] } \\
\text { - Cacco \&Moro [20] } \\
\text { - Elkin, Sullivan, \&Bers [21] } \\
\text { - Kandlhofer, Steinbauer, Hirschmugl-gaisch, \&Eck [22] } \\
\text { - Kazakof \&Bers [23] } \\
\text { - Somyurek [24] } \\
\text { - Datteri, Zecca, Laudisa, \&Castiglioni [25] } \\
\text { - Eck et al. [26] } \\
\text { - Ma \& Williams [27] } \\
\text { - Sullivan, Kazakoff, \& Bers [28] } \\
\text { - Kazakoff, Sullivan, \& Bers [29] } \\
\text { - Kazakoff \& Bers [30] } \\
\text { - McDonald \& Howell [31] } \\
\text { - Stoeckelmayr, Tesar, \& Hofmann [32] } \\
\text { - Wei, Hung, Lee, \& Chen [33] } \\
\text { - Highfield [34] } \\
\text { - Jojoa, Bravo, \& Cortés [35] } \\
\text { - Ruiz-del-Solar [36] } \\
\text { - Bers [38] } \\
\text { - Hussain, Lindh, \& Shukur [39] }\end{array}$ & \\
\hline Young Children's Conceptualization of Robots and Systems of Robots & 5 \\
\hline \multicolumn{2}{|l|}{$\begin{array}{l}\text { - Spektor-Precel \& Mioduser [40] } \\
\text { - Mioduser \& Kuperman [41] } \\
\text { - Slangen, Van Keulen, \& Gravemeijer [42] } \\
\text { - Mioduser, Levy, \& Talis [43] } \\
\text { - Levy \& Mioduser [44] }\end{array}$} \\
\hline Young Children's Processes and Strategies for Learning Robotics & 4 \\
\hline \multicolumn{2}{|l|}{$\begin{array}{l}\text { - Aladjem, Kuperman, \& Mioduser [45] } \\
\text { - Yuen et al. [46] } \\
\text { - Levy \& Mioduser [47] } \\
\text { - Mioduser \&Levy [48] }\end{array}$} \\
\hline Assessment of Young Children's Robotics Learning & 1 \\
\hline - Savard \& Freiman [49] & \\
\hline
\end{tabular}




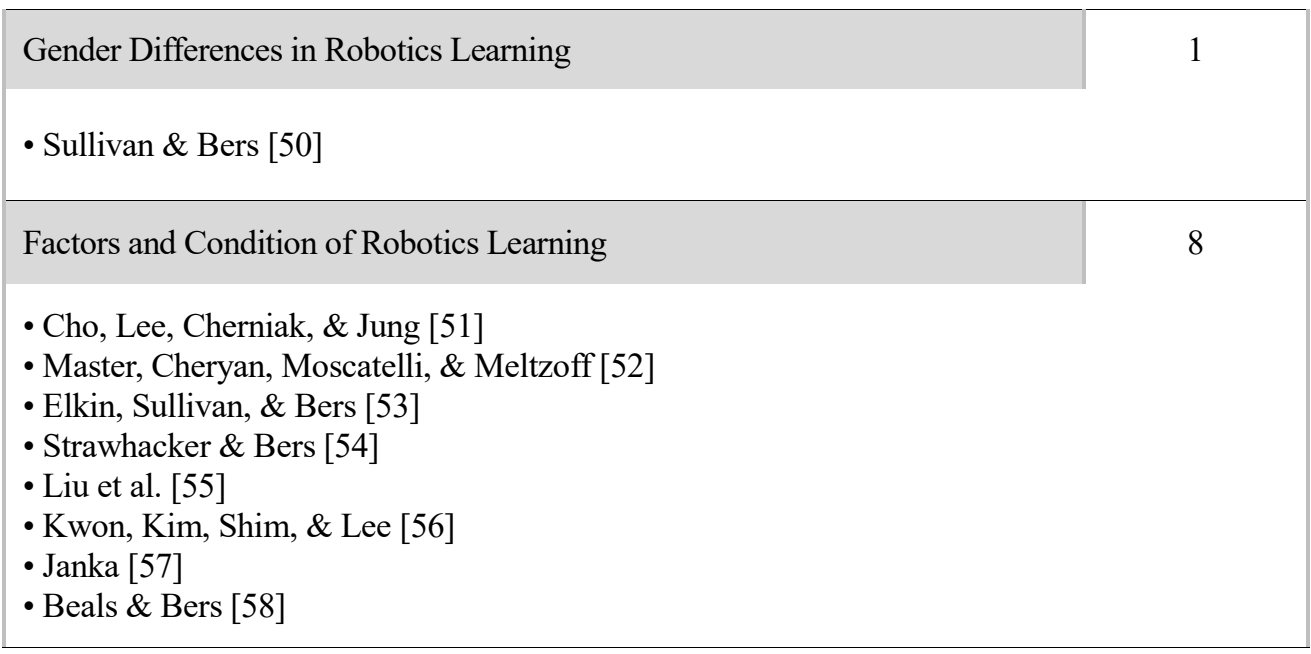

Our review showed that 30 of the reviewed studies $(61.2 \%)$ addressed the outcomes of robotics education for young children. This line of research focused on the advantages young children could gain by engaging in robotics activities (e.g., constructing robots to solve problems or programming robots to complete tasks). As for the outcomes of young children's robotics learning, the 30 studies addressed two key points.

First, the existing studies mainly focused on the kinds of knowledge (concepts), skills (practices), and attitudes (dispositions) that the young children achieved through robotics education. We summarized the details of these studies by categorizing them based on three domains (knowledge, skills, and attitudes) and providing specific examples of what the participant children learned (see Table 4).

Table 4. Domains and Contents of Robotics Education for Pre-K through $5^{\text {th }}$ Graders

\begin{tabular}{|c|c|c|}
\hline Domain & Sub-domain & Content \\
\hline \multirow{4}{*}{$\begin{array}{l}\text { Knowledge } \\
\text { (Concept) }\end{array}$} & $\begin{array}{l}\text { Subject-Oriented } \\
\text { Knowledge }\end{array}$ & $\begin{array}{l}- \text { Science } \bullet \text { Physics } \bullet \text { Computer-science } \\
\text { - Mathematics } \bullet \text { Geometry (Spatiality) } \\
\text { - Literacy }\end{array}$ \\
\hline & Knowledge of Robots & $\begin{array}{l}\text { - Physical parts of robots } \bullet \text { Functions of parts of } \\
\text { robots } \bullet \text { Basic components of different robots } \bullet \\
\text { Different morphologies of robots } \\
\text { - Different purposes of using robots } \\
\text { - Definition of robots } \bullet \text { History of robots }\end{array}$ \\
\hline & $\begin{array}{l}\text { Understanding of } \\
\text { Systems of Robots }\end{array}$ & $\begin{array}{l}\text { - Rules of adaptive behaviors of robots } \\
\text { - Artificial autonomous decision-making systems }\end{array}$ \\
\hline & $\begin{array}{l}\text { Computational } \\
\text { Concepts }\end{array}$ & $\begin{array}{l}\text { - Abstraction of commands (or symbols) } \\
\text { - Sequencing • Corresponding } \\
\text { - Repeated loop } \\
\text { - Parameters (Numbers parameters \& Sensor } \\
\text { parameters) }\end{array}$ \\
\hline \multirow[t]{2}{*}{$\begin{array}{l}\text { Practices } \\
\text { (Skills) }\end{array}$} & Programming & $\begin{array}{l}\text { - Analyzing } \bullet \text { Planning } \bullet \text { Sequencing } \\
\text { - Debugging (Trouble-shooting) } \\
\text { - Control flow } \bullet \text { Conditional Branching }\end{array}$ \\
\hline & $\begin{array}{l}\text { Construction of } \\
\text { Robots }\end{array}$ & $\begin{array}{l}- \text { Design } \bullet \text { Building } \bullet \text { Balance } \bullet \text { Stability } \\
- \text { Control }\end{array}$ \\
\hline
\end{tabular}




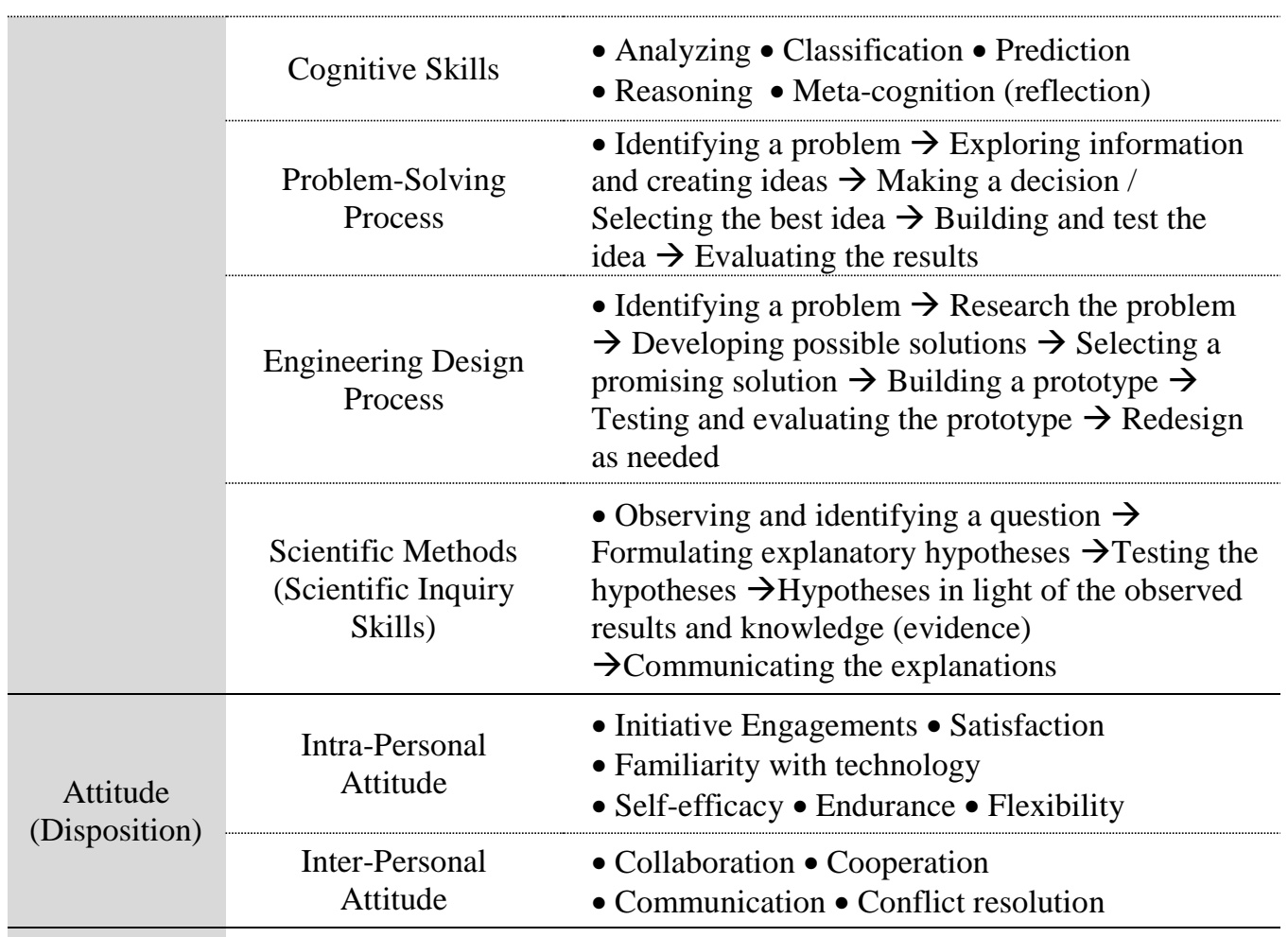

For example, using a micro-ethnographic case study approach, McDonald and Howell showed that a robotics project positively impacted 5- and 7-year-old children's literacy development and numeracy skills [31]. Julià and Antolí compared $6^{\text {th }}$ graders who did and did not participate in a 10-week robotics course [16]; the participating children developed statistically deeper spatial abilities than did the nonparticipating children. The quantitative and qualitative data from Eck and colleagues' pilot study indicated that robotics activities had an influence on kindergarten children's performance of the executive functions [26].

The researchers in these 30 studies also commonly reported on young children's intrapersonal and interpersonal attitudes (see Table 4), but these attitudes were not the main target of the studies. Nonetheless, the research emphasized that the robotics activities had unexpected but very impressive effects on the participants' intrapersonal and interpersonal dispositions.

The second point is centered on the participant learners' ages. The researchers paid attention to the extent to which the young children - including preschool and kindergarten students - were able to learn. Marian Bers and colleagues are key scholars in this area. For instance, Bers, Flannery, Kazakoff, and Sullivan described kindergarten children as being able to acquire higher levels of computational thinking (e.g., looping and numeric parameters) while presenting quantitative evidence [19]. In particular, this study used the level of computational thinking (looping with numeric parameters vs. conditional statements with sensor parameters) to compare the children's achievement. The results indicated that even kindergarten students were able to understand and perform techniques involving looping and numeric parameters.

In addition, Sullivan and Bers quantitatively compared the achievements of three age groups (pre-K, kindergarten, and $2^{\text {nd }}$ grade) for two knowledge aspects [12]: 1) robotics knowledge (e.g., the parts of the robot and their functions) and 2) programming knowledge (e.g., easy sequencing, hard sequencing, easy repeat loops with number parameters, advanced repeat loops with number parameters, easy sequencing with various conditional commands, easy repeat loops with sensor parameters, hard repeat loops with sensor parameters, and conditional branching). Interestingly, this study showed that children of all ages performed equally well, even on the advanced programming tasks. However, Sullivan and Bers reported that the youngest children (pre-K) needed to learn at a slower pace, have more repetitive experiences, and work one-on-one with adult assistants to achieve the equal levels. 
Given the key themes of the reviewed research, which were focused on the outcomes of robotics education, we found that the existing studies of robotics education support a positive view regarding the adoption of robotics curricula and technologies for teaching young children. In other words, this outcome-focused research affirms robotics education's pedagogical implications for young children.

We emphasize here that these outcome-focus studies support the idea that robotics education can be integrated into early childhood curricula. Despite revealing a somewhat passive view of technology's purpose in early childhood education, this review study's results show that robotics education can fulfill teaching and learning needs in many areas and that it can be integrated with early childhood curricula rather than remaining an extracurricular activity $[59,60]$.

In particular, the outcome-focused research on robotics education indicates that robotics education can be integrated with science and engineering education. Again, as Table 4 shows, the domains that young children learn in robotics education are parallel to the scientific and engineering practices suggested in the Next Generation Science Standards (NGSS) [61]. Although the NGSS differentiated scientific and engineering practices in some ways, robotics education can provide children with opportunities for direct engagement in both engineering design and scientific inquiry. The NGSS articulated eight engineering practices based on the engineering design process [61]. Robotics education has many practices in common with the engineering design process. Table 5 summarizes the aspects of robotics practices that are relevant to the NGSS engineering practices.

Table 5. Robotics Practices Relevant to Engineering Practices of the NGSS

\begin{tabular}{|c|c|c|}
\hline $\begin{array}{c}\text { Engineering } \\
\text { Practices in NGSS }\end{array}$ & Robotics Practices & Details \\
\hline Defining problems & $\begin{array}{l}\text { Identifying problems } \\
\text { /defining problems }\end{array}$ & $\begin{array}{l}\text { - Understanding specific situations } \\
\text { that have problems } \\
\text { - Identifying the purpose of } \\
\text { construction (or programming) } \\
\text { - Identifying specific environments } \\
\text { - Clarifying the problems }\end{array}$ \\
\hline $\begin{array}{l}\text { Developing and using } \\
\text { models }\end{array}$ & Creating prototypes & $\begin{array}{l}\text { - Testing designs } \\
\text { - Trouble-shooting the design }\end{array}$ \\
\hline $\begin{array}{l}\text { Planning and carrying } \\
\text { out investigations }\end{array}$ & $\begin{array}{l}\text { Researching } \\
\text { and Designing }\end{array}$ & $\begin{array}{l}\text { - Gathering information } \\
\text { - Identifying detail } \\
\text { factors/conditions for design } \\
\text { - Identifying possible/alternative } \\
\text { design } \\
\text { - Planning appropriate structures }\end{array}$ \\
\hline & $\begin{array}{l}\text { Building robots } \\
\text { /Programming robots }\end{array}$ & $\begin{array}{l}\text { - Constructing robots } \\
\text { - Programming robots }\end{array}$ \\
\hline $\begin{array}{c}\text { Analyzing and } \\
\text { interpreting data } \\
\text { Using mathematics } \\
\text { and computational } \\
\text { thinking } \\
\end{array}$ & $\begin{array}{c}\text { Testing } \\
\text { and Evaluating }\end{array}$ & $\begin{array}{l}\text { - Evaluating design } \\
\text { - Identifying errors in programming } \\
\text { - Evaluating the planning process }\end{array}$ \\
\hline Designing solutions & \multirow[b]{2}{*}{$\begin{array}{c}\text { Revising } \\
\text { and Improving }\end{array}$} & \multirow[b]{2}{*}{$\begin{array}{l}\text { - Identifying alternatives of designs } \\
\text { - Improving design } \\
\text { - Correcting errors in programming }\end{array}$} \\
\hline $\begin{array}{l}\text { Engaging in argument } \\
\text { from evidence } \\
\text { Obtaining, evaluating, } \\
\text { and communicating }\end{array}$ & & \\
\hline
\end{tabular}


information

As presented in Table 5, robotics practices and engineering design practices in the NGSS are not identical; however, nearly all of the eight practices overlap. Robotics practices can be defined in various ways depending on the curriculum and on the type of manipulatives. However, based on the outcomes shown in Table 4, robotics education can provide young children with experiences such as the robot design process in which the children design, construct, operate, and apply robots.

There is general agreement that the robot design process consists of two parts: engineering design and computer programming [62]. Obviously, these are interrelated within an iterative process. Thus, they cannot be understood or used separately. Considering the iterative nature of the robot design process, engineering design and computer programming together are a systematic set of engineering practices.

On the other hand, even when focusing on engineering design and computer programming individually (but still as parts of the entire robot design process), each can still be considered an opportunity for engaging in engineering practices. It is easy to conclude that engineering design for robots and the NGSS engineering practices share the same features [61]. To be specific, robotic engineering design is driven by the needs of practical applications for robots [63]; At the start of the engineering design process, children aim to produce the most effective design - robots. By targeting optimized outcomes (rather than a single, correct result), children can engage in model-based testing of their proposed robots using the empirical data that the robots generate. The children can also evaluate the robots in terms of the desired functions (e.g., pushing blocks or turning in front of obstacles), technological feasibility, aesthetic features (e.g., appearance, balance, and decoration), and context-specific conditions and constraints (e.g., the characteristics of the floor or a desk). While analyzing and evaluating their robot models, children can use many types of knowledge. They can also be involved in reasoning and argument practices that help them to decide on the robot that best meets the identified needs.

Computer programming activities also possess distinct features of the engineering practices that the NGSS delineated. Sullivan and Heffernan conceptualized robot programming as robotics practices that represent the programmers' modes of thinking and that are performed with distinct programming languages [64]. For this reason, from the robotics point of view, programming is a set of representative practices involving computational thinking. The existing research on robotics education has defined computational thinking as a systematic set of practices that includes debugging, correspondence, sequencing, control flow, and abstraction [65]. Thus, robot programming uses mathematics and computational thinking, which is one of the eight NGSS engineering practices.

Furthermore, viewed broadly, the entire process of robot programming can be seen as a set of engineering practices characterized as a comprehensive problem-solving process [59]. To be specific, in order to control the robots' behaviors, children first have to define certain programming tasks (i.e., the kinds of actions that the robots have to carry out or outputs they have to produce) and then analyze the constraints or conditions of the situated environments. In the actual programming stage, the children have to apply abstract programming concepts (e.g., iterations, input and output, commands, and loops) and skills (e.g., troubleshooting) to actualize the robots' behaviors. Most of all, while engaging in testing and evaluating practices, children need to reflect on what causes any mismatches between the intention of the programming and the actualized robot performance. This is the practice of debugging [66]. By detecting mismatches and correcting the programming errors that caused those mismatches, children can close the gap between the robots desired state and its observed state [48]. Through such gradual and iterative processes, children learn to solve problems by changing the robots until the targeted state is achieved. 
In this way, the outcome-focus studies of robotics education support the conclusion that robotics education can be integrated into scientific and engineering practices. This implies that robotics education can also be a useful strategy in broadening young participants' STEM learning. Equitable learning opportunities and easy access to science (or STEM more broadly) are core issues in science learning and teaching [67]. Regardless of the outcomes of robotics education, one of its most frequently mentioned advantages is its attractive power, as it fosters young students' interest in science learning and motivates them to take the initiative in their STEM learning [68]. The attractiveness of robotics activities has been superficially identified by stressing the robots' technological features (e.g., tangibility, appearance, and auto-animated performance) [69]. Robotics education can easily create meaningful entry points into STEM to target the needs of diverse young children. Rusk and colleagues noted that several aspects of robotics education support strategies that introduce young children to STEM learning and engagement [3]. These aspects include a theme-based approach, the combination of arts and engineering, and storytelling. Robotics activities are versatile, so they can be used to teach a variety of content, and young children's robotics activities can are adaptable to their individual needs and learning goals.

The outcome-focused studies also indicate the potential for robotics education to create a very low threshold for entry into STEM, even for students who have difficulty engaging in scientific inquiry [20]. Robotics activities can provide accessible opportunities for students to engage with intrapersonal mental habits (e.g., intellectual interest and curiosity, flexibility, perseverance, adaptability, self-management, and initiative) in natural and fun ways [27]. Therefore, based on robotics education's versatility and changeability, varied types and structures of robotics activities can be used to attract and guide young children based on their individual interests, needs, and tendencies, even for those who are not interested in science and those who are underrepresented in STEM.

However, considering the various purposes for adopting robotics education in early childhood education, it is a narrow view to conceptualize young children's robotics learning as being limited only to science and engineering practices or only to STEM learning. Of course, robotics education can be a concrete and effective pedagogical example in STEM education because it is interdisciplinary and allows for direct engagement with core STEM concepts and skills [52]. However, robotics education can also be merged with curricula from beyond the STEM disciplines. In previous research, children's participation in robotics activities contributed to their learning in multidisciplinary areas (e.g., languages and the arts) $[31,34]$.

\section{Discussion}

This systematic review study started with this research question: "What key topics does the existing research present with regard to young children's robotics learning?" We concluded that the recent research on young children's robotics learning has been weighted toward outcomefocused research. As we show above, the existing literature has mainly reported children's achievements in robotics learning in terms of knowledge, skills, and dispositions (attitudes) in various subject areas.

First, we suggest that this outcome-focused trend is a response to continuous criticism from the research community, which has argued that the benefits of robotics education should not be taken for granted and that the impact of robotics education should be reinforced with strong evidence.

Second, we suggest that outcome-focused findings support an instrumental view of robotics education in which it is not only a means to serve other subject areas but also an aid in young children's holistic development. The various learning outcomes in the three domains (knowledge skills, and attitudes) explicitly reveal the interdisciplinary and integrated nature of robotics education. In particular, robotics education has the pedagogical potential to be used in the 
teaching of science and engineering practices.

Third, the intrapersonal and interpersonal dispositions were both worth recognizing as outcomes of robotics education. Because these dispositions are aligned with 21 st-century skills and competences [70], the outcomes of robotics education can reveal its potential for not just STEM learning but also individual holistic development.

Lastly, because young children are rarely represented in the ranges of STEM learners, outcome-focused studies can contribute to raising expectations regarding young children's intellectual and technological capabilities. By providing empirical data, this line of study can also be helpful in clarifying the developmentally appropriate expectations for robotics learning.

On the other hand, the outcome-focused literature can be seen as weighted toward highlighting the advantages of robotics education more than the potential needs and challenges that young children face when learning robotics and accessing STEM areas. Thus, we argue that the research should be expanded to examine these young learners' needs and challenges by considering how robotics curricula, pedagogical interactions, and teaching methods can constrain or open up children's learning. These new research focuses can contribute to the development of pedagogically responsive robotics education for young children.

\section{Acknowledgments}

This work was supported by the Ministry of Education of the Republic of Korea and the National Research Foundation of Korea (NRF-2017S1A5A2A01025738).

This paper is a revised and expanded version of a paper entitled [Categorizing Meaningful Keywords in Young Children's Robotics Learning by Meta-Analysis] presented at [The $5^{\text {th }}$ International Conference on Interdisciplinary Research Theory and Technology, Daejeon University, Korea, 22, Dec. 2017].

\section{References}

[1] D. L. Zeidler, "STEM Education: A Deficit Framework for the Twenty First Century? A Sociocultural Socioscientific Response", Cultural Studies of Science Education, vol. 11, no. 1, (2016), pp. 11-26.

[2] K. Kumpulainen and J. Sefton-Green, "What is Connected Learning and How to Research It?", International Journal of Learning and Media, vol. 4, no. 2, (2012), pp. 7-18.

[3] N. Rusk, M. Resnick, R. Berg and M. Pezalla-Granlund, "New Pathways into Robotics: Strategies for Broadening Participation", Journal of Science Education and Technology, vol. 17, no. 1, (2008), pp. 5969.

[4] V. Chandra, "Developing Students' Technological Literacy Through Robotics Activities", Literacy Learning: The Middle Years., vol. 22, no. 3, (2014), pp. 24-29.

[5] S. Somyürek, "An Effective Educational Tool: Construction Kits for Fun and Meaningful Learning", International Journal of Technology and Design Education, vol. 25, no. 1, (2015). pp. 25-41.

[6] M. U. Bers, "Blocks to Robots: Learning with Technology in the Early Childhood Classroom", Teacher Collge, Columbia University, New York, (2007).

[7] D. Davies, D. Jindal-Snape, C. Collier, R. Digby, P. Hay and A. Howe, "Creative Learning Environments in Education-A Systematic Literature Review", Thinking Skills and Creativity, vol. 8, (2013), pp. 80-91.

[8] M. Petticrew and H. Roberts, "Systematic Reviews in the Social Sciences: A Practical Guide", John Wiley \& Sons, Oxford, UK, (2008).

[9] A. Eguchi, "Robotics as a Learning Tool for Educational Transformation", Proceedings of the 4th International Workshop Teaching Robotics, Padova, Italy, (2014) July.

[10] D. Lieto, M. Chiara, E. Inguaggiato, E. Castro, F. Cecchi, Gi. Cioni, M. Dell'Omo and C. Laschi, "Educational Robotics Intervention on Executive Functions in Preschool Children: A Pilot Study", Computers in Human Behavior, vol. 71, (2017), pp. 16-23.

[11] T. Kopcha, J. McGregor, S. Shin, Y. Qian, J. Choi, R. Hill, J. Mativo and I. Choi, "Developing an Integrative STEM Curriculum for Robotics Education Through Educational Design Research", Journal of Formative Design in Learning, vol. 1, no. 1, (2017), pp. 31-44.

[12] A. Sullivan and M. U. Bers, "Dancing Robots: Integrating Art, Music, and Robotics in Singapore's Early Childhood Centers", International Journal of Technology and Design Education, (2017). pp. 1-22.

[13] A. Sullivan, M. U. Bers and C. Mihm, "Imagining, Playing, and Coding with KIBO: Using Robotics to Foster Computational Thinking in Young Children", Proceedings of the International Conference on Computational Thinking Education, Hong Kong, (2017) July 13-15.

[14] F. Bennie, C. Corbett and A. Palo, "Building Bridges, Robots, and High Expectations", Odyssey: New Directions in Deaf Education, vol. 16, (2015), pp. 14-19. 
[15] M. Gordon, E. Rivera, E. Ackermann and C. Breazeal, "Designing a Relational Social Robot Toolkit for Preschool Children to Explore Computational Concepts", Proceedings of the 14th International Conference on Interaction Design and Children, Boston, (2015) June 21-24.

[16] C. Julià and J. Ò. Antolí, "Spatial Ability Learning Through Educational Robotics", International Journal of Technology and Design Education, vol. 26, no. 2, (2016), pp. 185-203.

[17] A. Sullivan and M. U. Bers, "Robotics in the Early Childhood Classroom: Learning Outcomes from an 8week Robotics Curriculum in Pre-kindergarten Through Second Grade", International Journal of Technology and Design Education., vol. 26, no. 1, (2016), pp. 3-20.

[18] G. Zaharija, S. Mladenović and I. Boljat, "Use of Robots and Tangible Programming for Informal Computer Science Introduction”, Procedia-Social and Behavioral Sciences, vol. 174, (2015), pp. 38783884 .

[19] M. U. Bers, L. Flannery, E. R. Kazakoff and A. Sullivan, "Computational Thinking and Tinkering: Exploration of an Early Childhood Robotics Curriculum", Computers \& Education, vol. 72, (2014), pp. 145-157.

[20] L. Cacco and M. Moro, "When a Bee Meets a Sunflower", In Proceedings of 4th International Workshop Teaching Robotics Teaching with Robotics and 5th International Conference on Robotics in Education, Padova, Italy, (2014) July.

[21] M. Elkin, A. Sullivan and M. U. Bers, "Implementing a Robotics Curriculum in an Early childhood Montessori Classroom”, Journal of Information Technology Education: Innovations in Practice, vol. 13, (2014), pp. 153-169.

[22] J. Eck, S. Hirschmugl-Gaisch, M. Kandlhofer and G. Steinbauer, "A Cross-generational Robotics Project Day: Pre-school Children, Pupils and Grandparents Learn Together", Journal of Automation Mobile Robotics and Intelligent Systems, vol. 8. (2014), pp. 12-19.

[23] E. R. Kazakoff and M. U. Bers, "Put Your Robot in, Put Your Robot Out: Sequencing Through Programming Robots in Early childhood", Journal of Educational Computing Research, vol. 50, no. 4, (2014), pp. 553-573.

[24] S. Somyürek, "An Effective Educational Tool: Construction Kits for Fun and Meaningful Learning", International Journal of Technology and Design Education, vol. 25, no. 1, (2015), pp. 25-41.

[25] E. Datteri, L. Zecca, F. Laudisa and M. Castiglioni, "Learning to Explain: The Role of Educational Robots in Science Education", Themes in Science and Technology Education, vol. 6, no. 1, (2013), pp. 29-38.

[26] J. Eck, S. Hirschmugl-Gaisch, A. Hofmann, M. Kandlhofer, S. Rubenzer and G. Steinbauer, "Innovative Concepts in Educational Robotics: Robotics Projects for Kindergartens in Austria”, Proceedings of Austrian Robotics Workshop, Australia, (2013).

[27] Y. Ma and D. Williams, "The potential of a First LEGO League Robotics Program in Teaching 21st Century Skills: An Exploratory Study", Journal of Educational Technology Development and Exchange (JETDE), vol. 6, no. 2, (2013), pp. 2-10.

[28] A. Sullivan, E. R. Kazakoff and M. U. Bers, "The Wheels on the Bot Go Round and Round: Robotics Curriculum in Pre-Kindergarten”, Journal of Information Technology Education, vol. 12, (2013), pp. 203219.

[29] E. R. Kazakoff, A. Sullivan and M. U. Bers, "The Effect of a Classroom-based Intensive Robotics and Programming Workshop on Sequencing Ability in Early childhood", Early Childhood Education Journal, vol. 41, no. 4, (2013), pp. 245-255.

[30] E. Kazakoff and M. U. Bers, "Programming in a Robotics Context in The Kindergarten Classroom: The Impact on Sequencing Skills", Journal of Educational Multimedia and Hypermedia, vol. 21, no. 4, (2012), pp. 371-391.

[31] S. McDonald and J. Howell, "Watching, Creating and Achieving: Creative Technologies as a Conduit for Learning in the Early Years", British Journal of Educational Technology, vol. 43, no. 4, (2012), pp. 641651.

[32] K. Stoeckelmayr, M. Tesar and A. Hofmann, "Kindergarten Children Programming Robots: a First Attempt", Proceedings of 2nd International Conference on Robotics in Education (RIE), (2011) September.

[33] W. Chun-Wang, H. I-Chun, L. Ling and C. Nian-Shing, "A Joyful Classroom Learning System with Robot Learning Companion for Children to Learn Mathematics Multiplication", The Turkish Online Journal of Educational Technology, vol 10, no. 2, (2011), pp 11-23.

[34] K. Highfield, "Robotic Toys as a Catalyst for Mathematical Problem Solving", vol. 15, no. 2, (2010), pp. 22-27.

[35] E. Jojoa, E. Bravo and E. Cortes, "Tool for Experimenting with Concepts of Mobile Robotics as Applied to Children's Education", IEEE Transactions on Education, vol. 53, no. 1, (2010), pp. 88-95.

[36] J. Ruiz-del-Solar, "Robotics-centered Outreach Activities: An integrated approach", IEEE Transactions on Education, vol. 53, no. 1, (2010), pp. 38-45.

[37] J. M. Chambers, M. Carbonaro and H. Murray, "Developing Conceptual Understanding of Mechanical Advantage Through the Use of Lego Robotic Technology", Australasian Journal of Educational Technology, vol. 24, no. 4, (2008). pp 387-401.

[38] M. U. Bers, "Project InterActions: A Multigenerational Robotic Learning Environment", Journal of Science Education and Technology, vol. 16, no. 6, (2007), pp. 537-552. 
[39] S. Hussain, J. Lindh and G. Shukur, "The Effect of LEGO Training on Pupils' School Performance in Mathematics, Problem Solving Ability and Attitude: Swedish data”, Journal of Educational Technology \& Society, vol. 9, no. 3, (2006), pp. 182-194.

[40] K. Spektor-Precel and D. Mioduser, "The Influence of Constructing Robot's Behavior on the Development of Theory of Mind (ToM) and Theory of artificial mind (ToAM) in Young Children", Proceedings of the 14th International Conference on Interaction Design and Children, Medford, MA, (2015) June 21-25.

[41] D. Mioduser and A. Kuperman, "Kindergarten Children's Perceptions of "Anthropomorphic Artifacts" with Adaptive Behavior", Proceedings of the Chais conference on Instructional Technologies Research 2012: Learning in the Technological Era, Raanana, Israel, (2012).

[42] L. Slangen, H. van Keulen and K. Gravemeijer, "What Pupils Can Learn from Working with Robotic Direct Manipulation Environments", International Journal of Technology and Design Education, vol. 21, no. 4, (2011), pp. 449-469.

[43] D. Mioduser, S. Levy and V. Talis, "Episodes to Scripts to Rules: Concrete-abstractions in Kindergarten Children's Explanations of a Robot's Behavior", International Journal of Technology and Design Education, vol. 19, no. 1, (2009), pp. 15-36.

[44] S. Levy and D. Mioduser, ““'Does It "Want" or "Was It Programmed To..."? Kindergarten Children's Explanations of an Autonomous Robot's Adaptive Functioning", International Journal of Technology and Design Education, vol. 18, no. 4, (2008), pp. 337-359.

[45] R. Aladjem, A. Kuperman and D. Mioduser, "Kindergarten Programming Goes Mobile: Should The Next Years Be About Ubiquity?", Proceedings of the 2017 Conference on Interaction Design and Children, Stanford, California, (2017) June 27-30.

[46] T. Yuen, M. Boecking, E. P. Tiger, A. Gomez, A. Guillen, A. Arreguin and J. Stone, "Group Tasks, Activities, Dynamics, and Interactions in Collaborative Robotics Projects with Elementary and Middle School Children", Journal of STEM Education: Innovations and Research, vol. 15, no. 1, (2014), pp. 3945.

[47] S. Levy and D. Mioduser, “Approaching Complexity Through Planful Play: Kindergarten Children's Strategies in Constructing an Autonomous Robot's Behavior", International Journal of Computers for Mathematical Learning, vol. 15, no. 1, (2010), pp. 21-43.

[48] D. Mioduser and S. Levy, "Making Sense by Building Sense: Kindergarten Children's Construction and Understanding of Adaptive Robot Behaviors", International Journal of Computers for Mathematical Learning, vol. 15, no. 2, (2010), pp. 99-127.

[49] A. Savard and V Freiman, "Investigating Complexity to Assess Student Learning from a Robotics-Based Task", Digital Experiences in Mathematics Education, vol. 2, no. 2, (2016), pp. 93-114.

[50] A. Sullivan and M. U. Bers, "Gender Differences in Kindergarteners' Robotics and Programming Achievement”, International Journal of Technology and Design Education, vol. 23, no. 3, (2013), pp. 691702.

[51] E. Cho, K. Lee, S. Cherniak and S. Jung, "Heterogeneous Associations of Second-Graders' Learning in Robotics Class", Technology, Knowledge and Learning, vol. 22, no. 3, (2017), pp. 465-483.

[52] A. Master, S. Cheryan, A. Moscatelli and A. N. Meltzoff, "Programming Experience Promotes Higher STEM Motivation Among First-grade Girls", Journal of Experimental Child Psychology, vol. 160, (2017), pp. 92-106.

[53] M. Elkin, A. Sullivan and M. U. Bers, "Implementing a Robotics Curriculum in an Early Childhood Montessori Classroom”, Journal of Information Technology Education: Innovations in Practice, vol. 13, (2014), pp. 153-169.

[54] A. Strawhacker and M. U. Bers, ““I Want My Robot to Look for Food”: Comparing Kindergartner's Programming Comprehension Using Tangible, Graphic, and Hybrid User Interfaces", International Journal of Technology and Design Education, vol. 25, no. 3, (2015), pp. 293-319.

[55] E. Liu, L. Chun-Hung, L. Pey-Yan, F. Han-Chuan and H. Huei-Tse, "An Analysis of Teacher-student Interaction Patterns in a Robotics Course for Kindergarten Children: A Pilot Study", TOJET: The Turkish Online Journal of Educational Technology, vol. 12, no. 1, (2013), pp. 12-18.

[56] D. Kwon, H. Kim, J. Shim and W. Lee, "Algorithmic Bricks: A Tangible Robot Programming Tool for Elementary School Students”, IEEE Transactions on Education, vol. 55, no. 4, (2012), pp. 474-479.

[57] P. Janka, "Using a Programmable Toy at Preschool Age: Why and How", Proceedings of International Conference of Simulation, Modeling and Programming for Autonomous Robots, Venice, Italy, (2008) November 3-4.

[58] L. Beals and M. U. Bers, "Robotic Technologies: When Parents Put Their Learning Ahead of Their Child's", Journal of Interactive Learning Research, vol. 17, no. 4, (2006), pp. 341-366.

[59] H. Altin and M Pedaste, "Learning Approaches to Applying Robotics in Science Education", Journal of Baltic Science Education, vol. 12, no. 3, (2013), pp. 365-377.

[60] O. Mubin, C. J. Stevens, S. Shahid, A. Al Mahmud and J. J. Dong, "A Review of the Applicability of Robots in Education", Journal of Technology in Education and Learning, vol. 1, no. 13, (2013), pp. 1-7.

[61] NGSS Lead States, "Next Generation Science Standards: For States, By States", The National Academies Press, Washinton, DC, (2013). 
[62] L. Flannery, L. B. Silverman, E. R. Kazakoff, M. U. Bers, P. Bontá and M. Resnick, "Designing ScratchJr: Support for Early Childhood Learning Through Computer Programming", Proceedings of the 12th International Conference on Interaction Design and Children, New York, (2013) June 24-27.

[63] C. M. Cunningham and S. C. William, "Teaching Engineering Practices", Journal of Science Teacher Education, vol. 25, no. 2, (2014), pp. 197-210.

[64] F. Sullivan and J. Heffernan, "Robotic Construction Kits as Computational Manipulatives for Learning in the STEM Disciplines", Journal of Research on Technology in Education, vol. 48, no. 2, (2016), pp. 105128.

[65] S. Y. Lye and J. J. L. Koh, "Review on Teaching and Learning of Computational Thinking Through Programming: What is Next for K-12?", Computers in Human Behavior, vol. 41, (2014), pp. 51-61.

[66] L. Seiter and B. Foreman, "Modeling the: Learning Progressions of Computational Thinking of Primary Grade Students", Proceedings of the Ninth Annual International ACM Conference on International Computing Education Research, San Diago, San Califonia, (2013) August 12-14.

[67] O. Lee and C. A. Buxton, "Diversity and Equity in Science Education: Research, Policy, and Practice. Multicultural Education Series", Teachers College Press, New York, (2010).

[68] M. E. Karim, S. Lemaignan and F. Mondada, "A Review: Can Robots Reshape K-12 STEM Education?", In Advanced Robotics and its Social Impacts, (2015), pp. 1-8.

[69] D. Alimisis, "Educational Robotics: Open Questions and New Challenges", Themes in Science and Technology Education, vol. 6, no. 1, (2013), pp. 63-71.

[70] B. Trilling and C. Fadel, "21st Century Skills: Learning for Life in Our Times", John Wiley \& Sons, San Francisco, Califonia, (2009).

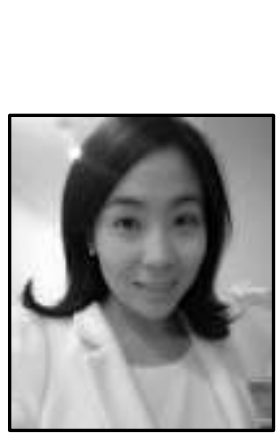

\section{Authors}

Sung-eun Jung, Sung-eun Jung is a doctoral candidate of Early Childhood Education in the Department of Educational Theory and Practice at the University of Georgia. She has participated in a series of research project providing robotics education programs to 3- to 8-year-old children. Her scholarly interests are in young children's engagement with materiality, including objects, spaces, and technologies. Also, she had interested in exploring ways of regaining attention to children's ways of learning with materials and bringing young children's agency into early childhood classroom learning. As a teacher educator, she has taught courses for undergraduate preservice teachers of the Early Childhood Education Program in the University of Georgia.

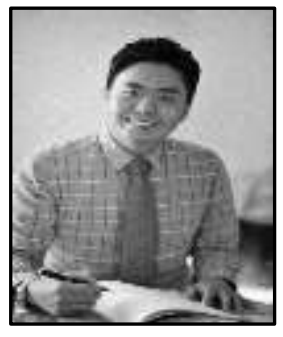

Eun-sok Won, Dr. Won is a noted English educator currently serving a professor with Mokwon University, as well as a director with the Corpus Education Publication Company and the Institute of Creativity and Humanity in South Korea. He has leveraged his passion for utilizing digital contents in education such as digital games, Al based contents, big data, smart devices and education contents. Also, he has focused on various practical issues in how gamification an intelligent interfaces based learning and teaching methods can best be applied to the language education. He was named to a 2007 Seoul Humanities Fellowship by the Seoul Metropolitan Government. Dr. Won has been included in Marquis Who's Who. As in all Marquis Who's Who biographical volumes, individuals profiled are selected on the basis of current reference value. 